\title{
HUBUNGAN MOTIVASI DENGAN EFIKASI DIRI PADA PASIEN DENGAN DIABETES MELITUS TIPE II DI RUMAH SAKIT UMUM GMIM PANCARAN KASIH MANADO
}

\author{
Mario E. Katuuk \\ Vandri D. Kallo \\ Program Studi Ilmu Keperawatan Fakultas Kedokteran \\ Universitas Sam Ratulangi Manado \\ Email : rioesau@unsrat.ac.id
}

\begin{abstract}
Motivation of each individual is related to the self-efficacy that each individual has. The low level of client motivation affects client's self-efficacy, so that self-care management of DM patients cannot run well. The purpose of this study is to know the relationship between motivation and self-efficacy in patients with type 2 diabetes mellitus at the GMIM Hospital Pancaran Kasih Manado in 2018. The Design of this study was descriptive analytical with cross sectional approach. The study was conducted at the GMIM Hospital Pancaran Kasih Manado. The sample used was 34 patients. The instruments used were questionnaire demographic characteristics of respondents, motivational questionnaires, and self-efficacy questionnaires tested using the Fisher Exact test. The results of the Fisher Exact statistic test are the relationship between motivation and self-efficacy of patients with Type 2 Diabetes Mellitus at GMIM General Hospital Pancaran Kasih Manado obtained $p=0.026(\alpha=0.05)$. The conclusion is that there is a relationship between motivation and self-efficacy of patients with Type 2 Diabetes Mellitus in RSU GMIM Pancaran Kasih Manado. Keywords: Motivation, Self-Efficacy.
\end{abstract}

\begin{abstract}
Abstrak: Motivasi dari setiap individu berkaitan dengan efikasi diri yang dimiliki oleh masingmasing individu tersebut. Tingkat motivasi klien yang rendah mempengaruhi efikasi diri klien, sehingga manajemen perawatan diri pasien DM tidak dapat berjalan dengan baik. Tujuan dalam penelitian ini ialah diketahui hubungan antara motivasi dengan efikasi diri pada pasien diabetes melitus tipe 2 di RSU GMIM Pancaran Kasih Manado tahun 2018.. Jenis penelitian yang digunakan adalah deskriptif analitik dengan pendekatan cross sectional. Penelitian dilaksanakan di RSU GMIM Pancaran Kasih Manado.. Sampel yang digunakan sebanyak 34 pasien. Instrumen yang digunakan kuesioner karakteristik demografi responden, kuesioner motivasi, dan kuesioner efikasi diri yang diuji menggunakan uji Fisher Exact. Hasil uji statistik Fisher Exact hubungan antara motivasi dengan efikasi diri pasien Diabetes Melitus Tipe 2 di Rumah Sakit Umum GMIM Pancaran Kasih Manado diperoleh nilai $p=0,026(\alpha=$ 0,05). Kesimpulan yaitu ada hubungan antara motivasi dengan efikasi diri pasien Diabetes Melitus Tipe 2 di RSU GMIM Pancaran Kasih Manado.
\end{abstract}

Kata Kunci: Motivasi, Efikasi Diri 


\section{PENDAHULUAN}

Diabetes Melitus tipe 2 adalah penyakit gangguan metabolik yang di tandai oleh peningkatan kadar glukosa darah akibat penurunan sekresi insulin yang progresif di latar belakangi oleh resistensi insulin (Soegondo, 2011). Proporsi kejadian diabetes tipe 2 mencapai $90-95 \%$ dari populasi 3 dunia yang menderita diabetes melitus (American Diabetes Association (ADA), 2017). Diabetes adalah penyakit tidak menular yang akan semakin meningkat jumlahnya di masa datang. Diabetes merupakan salah satu ancaman utama bagi kesehatan umat manusia pada abad ke 21. World Health Organization (WHO) membuat perkiraan bahwa pada tahun 2000 jumlah pengidap diabetes di atas umur 20 tahun berjumlah 150 juta orang dan dalam kurun waktu 25 tahun kemudian, pada tahun 2025, jumlah itu akan membengkak menjadi 300 juta orang (Sudoyo, Aru W, 2009). Apabila dibiarkan tidak terkendali dapat terjadi komplikasi metabolik akut maupun komplikasi vaskuler jangka panjang, baik mikroangiopati maupun makroangiopati (Lemone \& Burke, 2008; American Diabetes Association [ADA], 2010).

Penatalaksaan pada pasien diabetes melitus tipe 2 secara tepat adalah dengan mencegah atau memperlambat munculnya komplikasi baik dengan menerapkan perilaku self management dalam kehidupan seharihari meliputi diet sehat, aktivitas fisik, motivasi yang tinggi untuk tetap pada kondisi sehat. Kemampuan tubuh pasien diabetes untuk bereaksi dengan insulin dapat menurun, keadaan ini dapat menimbulkan komplikasi akut (seperti diabetes ketoasidosis dan sindrom hiperosmolar nonketotik) maupun kronik (seperti komplikasi makrovaskuler, mikrovaskuler, dan neuropati). Selain dari perilaku yang mampu mencegah penyakit tersebut seperti pengaturan pola makan yang sehat, aktivitas fisik, minum obat yang teratur, pemantauan glukosa darah dan perawatan diri sendiri dengan kemampuan dan keyakinan yang tinggi pada diri sendiri atau yang disebut dengan efikasi diri (Alwisol, 2014).

Berdasarkan data yang di peroleh dari Dinas Kesehatan Provinsi Sulawesi Utara, jumlah kasus DM di Provinsi Sulawesi Utara pada tahun 2015 berjumlah 3652 dan mengalami peningkatan pada tahun 2016 yang berjumlah 5083. Dan data yang diperoleh dari Dinas Kesehatan Kota Manado kasus DM di Kota Manado pada tahun 2015 berjumlah 2756 dan meningkat pada tahun 2016 dengan jumlah 3496 (Dinkes Provinsi Sulut, 2016). Data penyakit 3 tahun terakhir berdasarkan survei awal di RSU. Pancaran Kasih GMIM Manado didapatkan bahwa DM merupakan penyakit dengan jumlah kasus kedua terbanyak yaitu pada tahun 2014 terdapat 1875 pasien, pada tahun 2015 mengalamai peningkatan dengan jumlah kasus 3201 pasien 3 begitu pun pada tahun 2016 juga mengalami peningkatan dengan jumlah kasus 5261 pasien. Berdasarkan data awal yang didapatkan di RSU GMIM Pancaran Kasih manado, terdapat 2.042 kasus penyandang DM pada bulan JuliSeptember 2017 (Data Primer, 2018).

Wawancara yang dilakukan peneliti dengan 3 orang pasien diabetes mellitus di RSU GMIM Pancaran Kasih Manado, mengatakan bahwa motivasi pasien untuk pengobatan diabetes mellitus tipe 2 ini dapat berfluktuasi disebabkan oleh perawatan yang lama dan biaya yang besar sehingga dapat menimbulkan masalah psikologis seperti frustasi, cemas, dan depresi. Masalah psikologis ini dapat mempengaruhi motivasi klien untuk melakukan perawatan diri. Tingkat motivasi klien yang rendah dapat mempengaruhi efikasi diri klien, sehingga manajemen perawatan diri pasien DM tidak dapat berjalan dengan baik. Manajemen diri yang berjalan kurang baik akan berdampak pada keberhasilan penatalaksanaan pasien DMT2. Tujuan yang akan dicapai dalam penelitian ini ialah diketahui adanya hubungan antara motivasi dengan efikasi diri pada pasien diabetes melitus tipe 2 di 
Rumah Sakit Umum GMIM Pancaran Kasih Manado tahun 2018.

\section{METODE PENELITIAN}

Jenis penelitian ini menggunakan pendekatan cross-sectional karena penelitian ini bermaksud mengetahui ada tidaknya hubungan variable dependen terhadap variabel independen dalam satu kali pengukuran menggunakan alat ukur berupa kuesioner. Penelitian ini bertempat di Poliklinik Rumah Sakit Umum GMIM Pancaran Kasih Manado pada bulan Mei Oktober 2018. Populasinya terdapat 137 orang pasien penderita DMT2 namun untuk pengambilan sampelnya yaitu dengan metode nonprobability sampling dengan teknik purposive sampling, yaitu pengambilan sampel yang didasarkan atas pertimbangan dan sesuai dengan kriteria inklusi dan eksklusi maka di dapati sebanyak 34 pasien yang akan menjadi respondennya.

Instrumen yang digunakan dalam penelitian ini ada 3 kuesioner yaitu karakteristik demografi responden terdiri dari umur, jenis kelamin, tingkat pendidikan, status pernikahan, status sosial ekonomi, pekerjaan dan lama menderita DM, kuesioner motivasi yang terdiri dari 19 pernyataan yang terdiri dari alasan menjalani pengobatan dan pemeriksaan gula darah (8 item) serta alasan mematuhi aturan makan dan olah raga (11 item), dengan 4 poin skala likert yaitu 1 untuk sangat tidak setuju sampai 4 untuk sangat setuju. Hasil uji validasi dan reliabel dalam kuisioner ini telah dilakukan dalam penelitian Ariani (2011), dimana terdapat 2 pertanyaan yang tidak valid (nomor $5 \&$ 13). Kedua pertanyaan tersebut dibuang dan ditemukan 17 pertanyaan yang memenuhi hasil uji valid sehingga skor total yang diperoleh yaitu 17-68 dengan nilai alpha 0,839 dan nilai r 0,258-0,603. Dan yang ketiga yaitu kuesioner efikasi diri yang terdiri dari 20 pernyataan. Namun dalam penelitian ini hanya 15 pernyataan yang digunakan, dimana pernyataan tersebut terdiri dari diet (7 item), pengobatan (2 item), pemeriksaan gula darah (3 item), olah raga dan perawatan umum (3 item). Penilaiannya menggunakan 3 poin skala likert dengan 3 untuk mampu melakukan, 2 kadang mampu melakukan dan kadang tidak mampu serta 1 untuk tidak mampu melakukan, dengan skor total 15-45. Dengan hasil uji valid dan reliabelnya semua pernyataan dalam kuisioner efikasi diri ini dinyatakan valid dan reliabel dengan nilai alpha 0,904 dan nilai r 0,206 - 0,751. Menurut Arikunto (2016) batasan nilai untuk menilai sikap dan perilaku seseorang dapat digunakan nilai $\geq 75 \%-80 \%$ skor hasil untuk mencapai hasil yang baik.

Analisis Univariat bertujuan untuk mendeskripsikan karakteristik masingmasing variabel penelitian. Untuk data numerik (umur, jumlah penghasilan, lama DM). Sedangkan Analisis bivariat bertujuan untuk mengetahui adakah hubungan yang signifikan antara 2 variabel (Hastono, 2007). Analisis bivariat dilakukan untuk membuktikan hipotesa penelitian yaitu adakah hubungan antara motivasi dengan efikasi diri pasien DM tipe 2 di RSU GMIM Pancaran Kasih, peneliti menggunakan uji Fisher Exact. Uji Fisher Exact digunakan untuk menguji keterkaitan antara dua variabel katagorik dimana ada sel yang memiliki nilai harapan kurang dari 5 , dengan kata lain data yang terlibat dalam uji Fisher Exact sedikit. Dengan nilai $\alpha=$ 0,05 . Bila nilai $P \leq$ nilai $\alpha$, maka keputusannya adalah Ho ditolak.

\section{HASIL dan PEMBAHASAN}

1. Karakteristik Responden

a. Jenis Kelamin

Tabel 1. Distribusi Frekuensi Responden Berdasarkan Jenis Kelamin

\begin{tabular}{ccc}
\hline Jenis Kelamin & $\mathrm{n}$ & $\%$ \\
\hline Laki-laki & 19 & 55,9 \\
Perempuan & 15 & 44,1 \\
Total & 34 & 100,0 \\
\hline
\end{tabular}

Sumber: Data Primer, 2018 
Berdasarkan Tabel 1 dapat diketahui bahwa dari 34 responden dalam penelitian ini, berjenis kelamin laki-laki sebanyak 19 responden $(55,9 \%)$ dan perempuan sebanyak 15 responden $(44,1 \%)$

b. Pendidikan

Tabel 2. Distribusi Frekuensi Responden Berdasarkan Pendidikan

\begin{tabular}{ccc}
\hline $\begin{array}{c}\text { Pendidikan } \\
\text { Terakhir }\end{array}$ & $\mathrm{n}$ & $\%$ \\
\hline Tidak Sekolah & 5 & 14,7 \\
SD & 2 & 5,9 \\
SMP & 2 & 5,9 \\
SMA & 15 & 44,1 \\
S1 & 10 & 29,4 \\
Total & 34 & 100,0 \\
\hline
\end{tabular}

Sumber : Data primer, 2018

Tabel 2 di atas dapat diketahui bahwa sebagian besar responden memiliki tingkat pendidikan SMA sebanyak $44,1 \%$, S I sebanyak 29,4\%, Tidak Sekolah 14,7\%, SD dan SMP sebanyak 5,9\%.

\section{Analisis Univariat Variabel Penelitian}

a. Motivasi

Tabel 3. Distribusi responden berdasarkan motivasi

\begin{tabular}{ccc}
\hline Motivasi & $\mathrm{n}$ & $\%$ \\
\hline Kurang Baik & 11 & 32,4 \\
Baik & 23 & 67,6 \\
Total & 34 & 100,0 \\
\hline
\end{tabular}

Sumber : Data primer, 2018

Data dari Tabel 3 di atas menunjukkan bahwa sebagian besar responden memiliki motivasi yang baik yaitu sebanyak 23 responden $(67,6 \%)$ sedangkan motivasi yang kurang baik sebanyak 11 responden $(32,4 \%)$. Hasil penelitian menunjukkan bahwa sebagian besar responden memiliki motivasi yang baik yaitu sebesar $67,6 \%$. Asumsi peneliti yaitu motivasi responden yang baik dikarenakan responden merasa banyak orang akan senang jika responden melakukan pengobatan, percaya bahwa pengobatan akan memperbaiki kesehatan, badan terasa baik jika melakukan pengobatan, senang jika gula darah berada dalam rentang yang normal, tidak ingin mengecewakan orang lain, orang lain akan senang jika melakukan pengobatan, penting bagi kesehatan, malu jika tidak melakukan pengobatan, memperhatikan makanan dan olah raga yang dilakukan, merasa bersalah jika tidak mengontrol makanan, berolah raga dengan teratur serta merasakan tantangan untuk belajar bagaimana hidup dengan DM.

Motivasi sangat berperan dalam perawatan mandiri karena motivasi adalah suatu dorongan atau sesuatu yang mendorong seseorang bertingkah laku untuk mencapai tujuan tertentu. Motivasi dapat memberikan pengaruh terhadap efikasi diri pasien DM tipe 2 dalam perawatan diri. Motivasi yang tinggi akan memiliki frekuensi perawatan diri yang baik terutama untuk diet dan pemeriksaan kadar gula darah (Ariani dkk, 2012). Motivasi diri pada dasarnya berasal dari dalam diri setiap individu, akan tetapi banyak faktor yang mepengaruhinya. Pada prinsipnya, seseorang yang memiliki motivasi yang tinggi, akan berusaha mewujudkan apa yang tengah diinginkannya, misalnya pada penderita DM yang diharuskan menjalankan pengobatan, motivasi yang tinggi mempengaruhi fikiran untuk melaksanannya dan kemudian diaplikasikan dengan terbentuknya suatu perbuatan (melakukan pengobatan), apabila berhasil orang yang bersangkutan akan merasa puas Responden yang memiliki motivasi yang baik akan selalu menunjukkan perilaku dan keyakinan yang baik dalam melakukan suatu usaha tertentu (Notoadmodjo, 2010).

\section{b. Efikasi Diri}

Tabel 4. Distribusi responden berdasarkan Efikasi Diri

\begin{tabular}{ccc}
\hline Efikasi Diri & $\mathrm{n}$ & $\%$ \\
\hline Kurang Baik & 12 & 35,3 \\
Baik & 22 & 64,7 \\
Total & 34 & 100,0 \\
\hline
\end{tabular}

Sumber : Data primer, 2018 
Tabel 4 di atas menunjukkan bahwa sebagian besar responden memiliki efikasi diri yang baik yaitu sebanyak 22 responden $(64,7 \%)$ sedangkan efikasi diri yang kurang baik sebanyak 12 responden $(35,3 \%)$. Hasil penelitian menunjukkan bahwa sebagian besar responden memiliki efikasi diri yang baik yaitu sebesar $64,7 \%$. Peneliti berasumsi bahwa fikasi diri responden yang baik dikarenakan responden mampu memeriksa gula darah sendiri jika perlu, mengoreksi gula darah sendiri ketika hasil gula darah tinggi, mampu memilih makanan yang benar, memeriksa keadaan kaki jika ada kelainan kulit atau luka, penyesuaian makanan ketika sakit, mengikuti aturan makan yang sehat, berolahraga, menyesuaikan rencana makan ketika berolahraga, mengikuti pola makan yang sehat. Mengikuti penyesuaian rencana makan, mengatur dan minum obat seperti yang telah ditentukan dan mampu melakukan penyesuaian pengobatan ketika sakit.

Efikasi diri berhubungan dengan situasi yang spesifik, yang tidak berlaku untuk konsep-konsep terkait seperti harga diri, kepercayaan diri dan locus of kontrol. Untuk setiap individu berhak menentukan, apakah dia harus percaya diri atau tidak,tetapi bukan apakah individu ini umumnya memiliki ukuran efikasi diri yang tinggi atau rendah. Keberhasilan bukanlah ciri kepribadian, tetapi mudah untuk mempengaruhi karakteristik yang ketat situasi dan tugas yang terkait. Efikasi diri mendorong proses kontrol diri untuk mempertahankan prilaku yang dibutuhkan dalam mengelola perawatan diri pada pasien diabetes mellitus. Keberhasilan pengelolaan diabetes melitus tergantung pada informasi tentang diabetes melitus tipe 2, motivasi, dan efikasi diri pasien untuk melakukan perawatan diri yang dirancang untuk mengontrol gejala psikologis maupun komplikasi (Ariyani, 2011).
Peneliti berasumsi bahwa hasil efikasi diri yang baik pada pasien DM tipe 2 di RSU GMIM Pancaran Kasih ini tidak lepas dari beberapa faktor pendukungnya. Faktor pendukung tersebut dapat berasal dari Rumah Sakit, dalam hal ini tenaga kesehatan yang melakukan pengobatan terhadap pasien, dukungan keluarga, sumber informasi. Efikasi diri yang kurang baik tentu akan menimbulkan dampak psikologis yang muncul akibat penyakit DM tipe 2 karena seperti yang kita ketahui DM tipe 2 merupakan salah satu penyakit kronis. Efikasi diri dapat ditingkatkan dengan pemberian informasi mengenai diabetes melitus tipe 2 itu sendiri, sehingga tingkat pengetahuan pasein akan bertambah mengenai manajemen kontrol diabetes.

3. Hubungan Motivasi dengan Efikasi Diri pada Pasien Diabetes Melitus Tipe 2 di Poliklinik Interna Rumah Sakit Umum GMIM Pancaran Kasih Manado.

Tabel 5. Hubungan Motivasi dengan Efikasi Diri pada Pasien Diabetes Melitus Tipe 2 di Poliklinik Interna Rumah Sakit Umum GMIM Pancaran Kasih Manado

\begin{tabular}{|c|c|c|c|c|c|c|c|}
\hline \multirow{3}{*}{ Motivasi } & \multicolumn{4}{|c|}{ Efikasi Diri } & \multirow{2}{*}{\multicolumn{2}{|c|}{ Total }} & \multirow{3}{*}{$\begin{array}{c}\text { Nilai } \\
\mathrm{p}\end{array}$} \\
\hline & \multicolumn{2}{|c|}{$\begin{array}{c}\text { Kurang } \\
\text { Baik }\end{array}$} & \multicolumn{2}{|c|}{ Baik } & & & \\
\hline & $\mathrm{n}$ & $\%$ & $\mathrm{n}$ & $\%$ & $\mathrm{n}$ & $\%$ & \\
\hline $\begin{array}{l}\text { Kurang } \\
\text { Baik }\end{array}$ & 7 & 20,6 & 4 & 11,8 & 11 & 32,4 & \\
\hline Baik & 5 & 14,7 & 18 & 52,9 & 23 & 67,6 & 0,026 \\
\hline Total & 12 & 35,5 & 22 & 64,7 & 34 & 100 & \\
\hline
\end{tabular}

Sumber : Data Primer, 2018

Data pada Tabel 5 di atas menunjukkan bahwa dari 11 responden dengan motivasi yang kurang baik, 20,6\% memiliki efikasi diri yang kurang baik sedangkan sebanyak $11,8 \%$ memiliki efikasi diri yang baik. Data juga menunjukkan bahwa dari 23 responden yang memiliki motivasi yang baik, 52,9\% memiliki efikasi diri yang baik sedangkan sebanyak $14,7 \%$ memiliki efikasi diri yang kurang baik. Dilihat dari 
nilai signifikansi sebesar 0,026 dengan demikian probabilitas (signifikansi) lebih kecil dari $0,05 \quad(0,026<0,05)$, maka ada hubungan yang signifikan antara motivasi dengan efikasi diri pasien Diabetes Melitus Tipe 2 di Poliklinik Interna Rumah Sakit Umum GMIM Pancaran Kasih Manado.

Berdasarkan hasil analisis bivariat dengan menggunakan uji Chi-square didapat bahwa nilai $\mathrm{p}=0,026$. Nilai $\mathrm{p}<$ 0,05 menunjukkan bahwa ada hubungan antara motivasi dengan efikasi diri pada pasien DM tipe 2 di Ruangan Perawatan dan Poliklinik Interna RSU GMIM Pancaran Kasih Manado. Hasil penelitian ini secara tidak langsung mendukung teori Ryan dan Deci, salah satu faktor yang mempengaruhi diabetes self management yaitu motivasi. Motivasi merupakan variabel yang signifikan terhadap self care diabetes, terutama dalam mempertahankan diet dan monitoring gula darah. Seseorang dapat termotivasi oleh tujuan dan harapan yang diinginkan. Motivasi berkorelasi positif dengan proses berubah, termasuk perubahan gaya hidup. Individu dengan motivasi yang tinggi akan terlihat pada perilakunya. Terbentuknya motivasi pada diri seseorang dalam menjalankan pengelolaan tidak hanya didasarkan tingkat pendidikan, pengalaman pribadi tentang kegagalan, keberhasilan dan lingkungan dalam pengelolaan juga dapat menjadi dasar motivasi penderita untuk melaksanakan perawatan diri yang baik. Motivasi merupakan faktor penting bagi penderita diabetes, karena motivasi yang ada pada diri penderita mampu memberikan dorongan yang kuat untuk melakukan self management diabetes (Ernawati, dkk, 2015).

Lingkungan sosial, keluarga dan tenaga kesehatan yang ada di rumah sakit berpengaruh dalam meningkatkan motivasi dan perubahan perilaku pasien. Dukungan keluarga yang suportif akan mencegah atau menurunkan gejala depresi pada pasien DM tipe 2. Depresi dapat berkontribusi terhadap penurunan fungsi fisik dan mental yang dapat menyebabkan pasien DM kehilangan motivasi untuk melakukan pengobatan maupun perawatan diri harian. Hal ini dapat menyebabkan gangguan control glikemik dan beresiko terjadinya komplikasi yang lebih lanjut (Aryani, dkk, 2012).

Penderita yang memiliki dasar motivasi dari aspek kebutuhan dan keyakinan yang baik akan mengalami peningkatan yang signifikan dalam manajemen diri diabetes. Keyakinan sebagai dimensi dari motivasi mempunyai hubungan yang signifikan terhadap efektifitas penatalaksanaan diabetes. Keyakinan diri yang tinggi akan berpengaruh terhadap kepatuhan. Seorang individu yang memiliki motivasi yang tinggi akan memperlihatkan perilaku dan keyakinan yang baik dalam melakukan tugas tertentu. Melihat pentingnya motivasi internal maupun eksternal terhadap pelaksanaan diabetes self management, maka menjadi penting bagi perawat untuk menentukan intervensi dalam meningkatkan motivasi dengan memberikan pengetahuan melalui pendidikan kesehatan dan konseling, motivasi, dukungan, arahan kepada klien dan keluarga agar mempertahankan aktifitas self management dalam kehidupan sehari-hari sehingga kestabilan gula darah dapat tercapai. Perawat melakukan evaluasi terhadap motivasi penderita yang datang dipelayanan kesehatan agar tetap semangat untuk melakukan perilaku self management diabetes (Purwanti, 2014).

Penelitian yang dilakukan oleh Kusuma (2013) menunjukkan ada hubungan yang bermakna antara motivasi dengan efikasi diri $(p=0,000)$. Motivasi menjadi faktor yang dominan mempengaruhi efikasi diri dalam perawatan mandiri DM. Seseorang yang memiliki motivasi yang tinggi akan menunjukkan hasil yang positif dalam pengelolaan DM. Penelitian yang dilakukan oleh Purwanti (2014) menunjukkan bahwa sebagian besar responden yang memiliki motivasi yang baik menunjukkan efikasi diri yang baik yaitu sebanyak 32 responden $(58,2 \%)$. 
Hasil analisa statistic menunjukkan bahwa ada hubungan antara motivasi dengan efikasi diri $(\mathrm{p}$ value $=0.039)$.

\section{SIMPULAN}

Berdasarkan hasil penelitian ini, kesimpulan yang dapat diambil yaitu:

1. Motivasi pasien diabetes melitus tipe 2 di RSU GMIM Pancaran Kasih Manado memiliki motivasi yang baik.

2. Efikasi diri pasien diabetes melitus tipe 2 di RSU GMIM Pancaran Kasih Manado memiliki efikasi diri yang baik.

3. Terdapat hubungan yang signifikan antara motivasi dengan efikasi diri pada pasien diabetes melitus tipe 2 di RSU GMIM Pancaran Kasih Manado.

\section{DAFTAR PUSTAKA}

ADA (American Diabetes Association)., 2010. Diagnosis and Classification of Diabetes Mellitus. Diabetes Care Vol.33: S62-9

ADA (American Diabetes Association)., (2017). "Standards of Medical Care in Diabetes 2017”. Vol. 40. USA : ADA

Aru W, Sudoyo. (2009). Buku Ajar Ilmu Penyakit Dalam, jilid II, edisi V. Jakarta: Interna Publishing.

Alwisol. (2014). Psikologi Kepribadian edisi revisi: UMM

Ariani, Y. (2011). Hubungan antara motivasi dengan efikasi diri pasien DM tipe 2 dalam konteks asuhan keperawatan di RSUP. H. Adam Malik Medan. Depok: FIK UI.

Ariani, Y., R. Sitorus dan D. Gayatri. 2012. Motivasi dan Efikasi Diri Pasien Diabetes Melitus Tipe 2 dalam Asuhan Keperawatan. Jurnal Keperawatan Indonesia 15 (1): 29-38.

Arikunto, S. (2016). Prosedur Penelitian Suatu Pendekatan Praktek. Jakarta, PT.Rineka Cipta.
Ernawati., E. P. Setiawati dan T. Kurniawan. 2015. Pengaruh Motivasi Internal dan Eksternal terhadap Self Management di Wilayah Kecamatan Gombong Kabupaten Kebumen. JSK 1 (2): 55-62.

Dinas Kesehatan Provinsi Sulawesi Utara. (2011) Profil Kesehatan Provinsi Sulawesi Utara 2010. Edisi 2011. Manado: Balai Data Surveilans Dan Sistem Informasi Kesehatan..

Hastono. (2007) Analisa Data Kesehatan. Jakarta : FKM. UI.

Notoatmodjo, S. 2010. Metodologi Penelitian Kesehatan. Jakarta : Rineka Cipta

Purwanti, L. E. 2014. Hubungan Motivasi dengan Efikasi Diri Pasien DM Tipe 2 dalam Melakukan Perawatan Kaki di Wilayah Kerja Puskesmas Ponorogo Utara. Gaster 11 (2): 68-77.

Soegondo, S., 2011. Diagnosis dan Klasifikasi Diabetes Melitus Terkini dalam: Soegondo, S., Soewondo, P., Subekti, I., Editor. Penatalaksanaan Diabetes Melitus Terpadu bagi dokter maupun edukator diabetes. Jakarta: Fakultas Kedokteran Universitas Indonesia 